\title{
A COGNITIVE ENERGY DISTRIBUTION SYSTEM
}

\author{
SANUKRISHNAN S.B. \\ PG SCHOLAR, ELECTRONICS \& COMMUNICATION DEPT. \\ HiNDUSTHAN INSTITUTE OF TECHNOLOGY, COIMBATORE.
}

\begin{abstract}
This is a complete automated solution for the existing energy distribution and monitoring system in India, which can monitor the meter readings continuously and take necessary actions to maintain the power grid stable. A Power Line Communication (PLC) based modem is integrated with each electronic energy meter. Through PLC the meters communicate with the coordinator. Coordinator makes use of GPRS modem to upload/download data to/from internet. A personal computer with an internet connection at the other end, which contains the database acts as the billing point. Live meter reading sent back to this billing point periodically and these details are updated in a central database. An interactive, user friendly graphical interface is present at user end. All the energy logs, notices from the Government, billing details and average statistics will be available here. The system splits the loads into critical loads and non critical loads. This makes the distribution system more intelligent. More over prior information about the power cuts can be done. We can easily implement many add-ons such as energy demand prediction, real time dynamic tariff as a function of demand and supply and so on.
\end{abstract}

\section{KEYWORDS}

AMR, Arduino, Dynamic tariff, Energy monitoring, Touch screen.

\section{INTRODUCTION}

India have $228.722 \mathrm{GW}$ capacity electricity distribution system, which is World's 5 th largest. Total expenditure in this section is about 12.58 trillion rupees and it is very sad to realize that more than $90 \%$ of energy that is used for electricity production is being wasted. This occurs during production, transmission, and consumption in many ways. More over energy theft is becoming a common practice. Also we saw that power failure affected more than 300 million people in Punjab, Haryana, Uttar Pradesh, Himachal Pradesh and Rajasthan states on 30th July 2012. All these statistics means that India is lacking a strong energy distribution and monitoring system.

This paper presents the design of energy monitoring system with an interactive meter. It is associated with GPRS, Power line communication, and web interface for automating billing and monitoring. It replaces traditional meter reading methods and enables remote access of existing energy meter by the energy provider. Also they can monitor the meter readings regularly without the person visiting each house.

Arduino board is used as the processing unit in the energy meter. It is a single-board microcontroller to make using electronics in multidisciplinary projects more accessible. The

DOI : $10.5121 /$ ijp2p.2014.5201 
hardware consists of an open-source hardware board designed around an 8-bit Atmel AVR microcontroller, or a 32-bit Atmel ARM. The software consists of a standard programming language compiler and a boot loader that executes on the microcontroller. Arduino boards can be purchased pre-assembled or as do-it-yourself kits.

Power line is used as the communication medium. PLC carries data on a conductor that is also used simultaneously for AC electric power transmission or electric power distribution to consumers. It is also known as power line carrier, Power Line Digital Subscriber Line (PDSL), mains communication, power line telecommunications, or Power Line Networking (PLN). A wide range of power line communication technologies are needed for different applications, ranging from home automation to Internet access which is often called Broadband over Power Lines (BPL). Most PLC technologies limit themselves to one type of wires (such as premises wiring within a single building), but some can cross between two levels (for example, both the distribution network and premises wiring). Typically transformers prevent propagating the signal, which requires multiple technologies to form very large networks. Various data rates and frequencies are used in different situations.

\section{Proposed System}

Figure 1 shows the complete structure of the proposed system. A number of energy meters that can communicate with a coordinator through power line are present. Coordinator collects the readings from meters as well as it act according to the instructions from the controlling station. Actions include connecting and disconnecting loads, displaying tariffs etc. number of coordinators in a system is determined by the number of customers and the geometrical distance. Coordinators update all the readings in the internet, which can be instantaneously monitored in the controlling station. Power consumption of individual users and their history will be available here. Instant billing and disconnection/connection of users are also available. Entire system mainly consists of following sections and features.

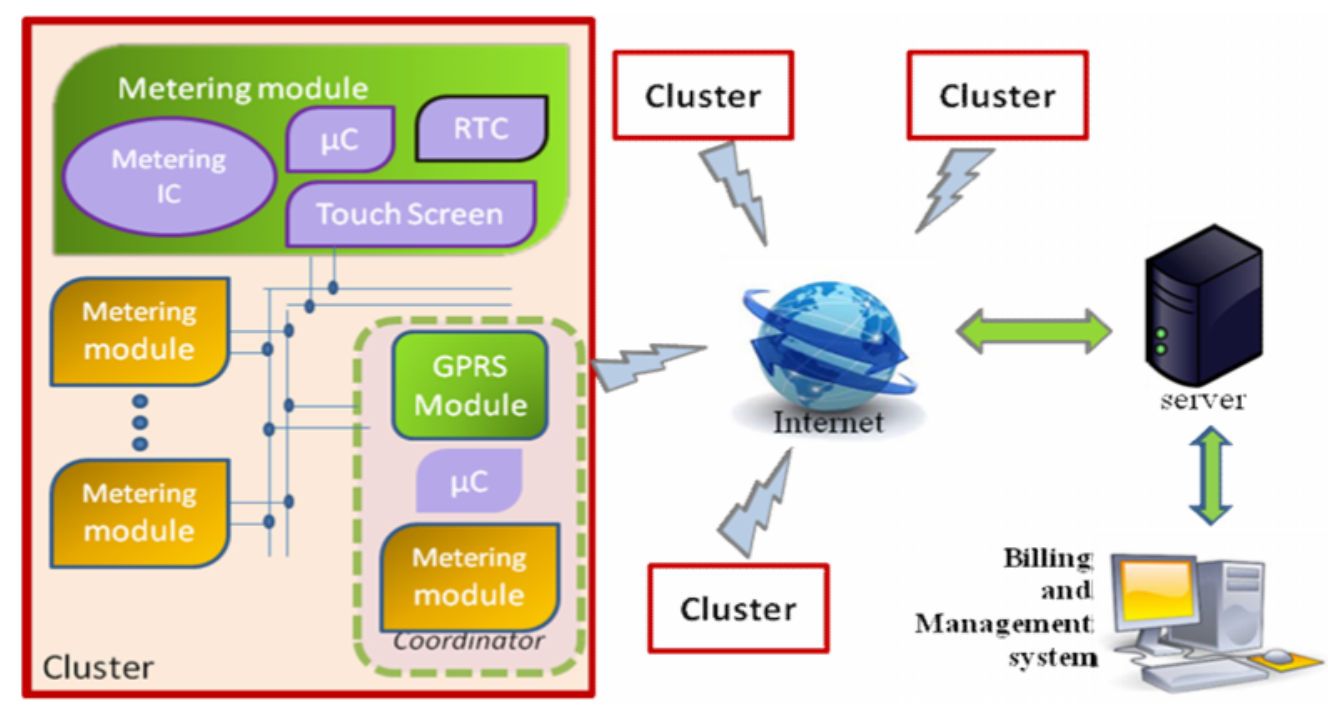

Figure.1 Block Diagram of complete system 


\subsection{Metering Module}

Each metering module consists of a metering IC, a microcontroller, Real Time Clock (RTC) and a touch screen. Metering IC will generate the pulses according to the power consumption. This will be processed by the microcontroller and stored in a SD card. Touch screen makes the system more interactive and usable. It is capable of displaying the power consumption per day, per week as well as per month. It can display the statistics in a bar graph, which makes the user analysis the power consumption easily. All the notices and information from the government such as power cut schedule, billing date reminder etc. Power line modem will modify the communication signals and transmit/receive the required information.

\subsection{Coordinator}

A number of meters are connected to a single coordinator through PLC. Each coordinator will have a GPRS modem to get connected to the internet. An additional meter present here will calculate the total power distributing to that particular area, and the coordinator compare this reading to the sum of individual meters to detect energy theft. Number of meters that can get connected to a single coordinator depends on the distance and physical conditions of that area. Group of a coordinator and meters can be called as a cluster.

\subsection{Server and Management System}

This is the centralized controlling part. All dates will be updated here. Unit is located at the Electricity Board. The officers can easily view, analyze and control each individual meters. Even the connection and disconnection can be dome remotely. Individual profiles will be there for each consumer. The customers can do online payment and other options.

\subsection{Energy Theft Detection}

Use of auxiliary meters allows us to detect the energy theft. The coordinator compares the auxiliary meter reading and the sum of other meter readings to make a conclusion. If these readings match approximately, that indicates no theft. The same system can be used to find out the energy losses. Sub meters can also include if necessary. Figure. 2 depicts the energy theft detection concept.

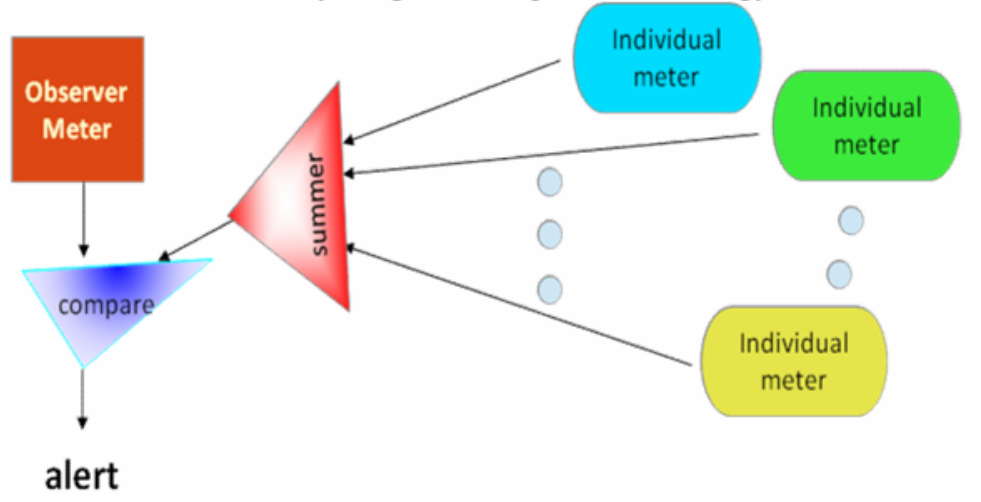

Figure.2 Energy theft detection. 


\subsection{Critical and Non Critical Load Separation}

The entire load in each destination is separated into two-critical and non-critical. This system has the ability to control these loads independently. Very low power devices can be connected to critical loads such as CFL lamps. During the power shutdown, the critical loads can be remained on so that the basic requirements of user will get satisfied without any burden to the electricity board.

\subsection{Real Time Dynamic Tariff}

Since the load requirement is not balanced and randomly varying, and the production is almost fixed, the government may have to borrow or lease electricity. The entire grid system should be balanced so as to ensure a stable distribution system. Since we have a continuous interaction with the meter, tariffs can be varied instantaneously and can be displayed in the meter. When the demand is high, tariff will be more and more consumers try to reduce consumption and vice versa. This increases the stability, and the grid should be balanced. For example powering on a mixer grinder at the night, which is the peak time, rather than the less requirement time in a home is not advisable.

\subsection{Demand Analysis and Prediction}

Since all the statistics such as time based, area based, season based are available, and the load requirements in the upcoming can be easily approximated by statistical method. This makes the distribution system more reliable and stable.

\section{HARDWARE DESIGN}

Entire hardware section can be sub divided into two- design of meter and design of coordinator. Each cluster consists of a coordinator and a number of meters. Number of clusters defines the system.

\subsection{Design of Energy Meter}

An Arduino Mega developer board is used as the main part of meter's prototype. In addition to that a TFT screen with touch screen from ITEAD Studio is used. A PLC modem should also be interfaced for the complete functionality. 


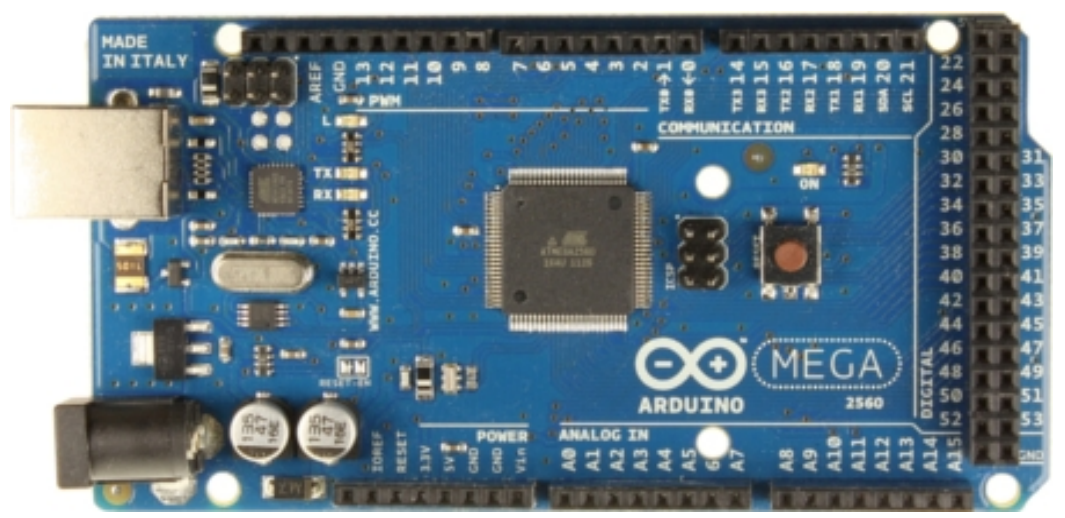

Figure.3 Arduino Mega

The Arduino Mega 2560 is a microcontroller board based on the ATmega2560. It has 54 digital input/output pins, 16 analog inputs, 4 UARTs (hardware serial ports), a $16 \mathrm{MHz}$ crystal oscillator, a USB connection, a power jack, an ICSP header, and a reset button. It contains everything needed to support the microcontroller; simply connect it to a computer with a USB cable or power it with a AC-to-DC adapter or battery to get started. The Mega is compatible with most shields designed for the Arduino Duemilanove or Diecimila.

I have used an ITEAD 2.8 TFT LCD touch shield. 2.8" TFT Touch Shield is an Arduino UNO/ Mega compatible multi coloured TFT display with a touch-screen and SD card socket. It is available in an Arduino shield compatible pin out for attachment. The TFT driver is based on ILI9325DS with 8bit data and 4bit control interface. It can work with both $3.3 \mathrm{~V}$ and $5 \mathrm{~V}$, so it can display on Chipkit UNO32 and Simple cortex as well.

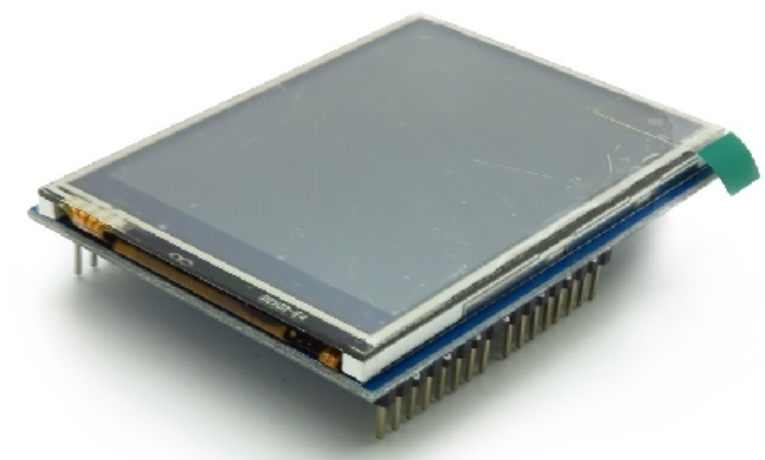

Figure.4 ITEAD TFT LCD touch shield

User touch screen is designed with 6 main screens. The welcome screen will get opened when the system get switched on. It is shown in Figure.5. Home screen will come automatically after a few seconds and it display the energy consumption per day per week and per month as in figure 6 . 
International Journal of Peer to Peer Networks (IJP2P) Vol.5, No.2, May 2014

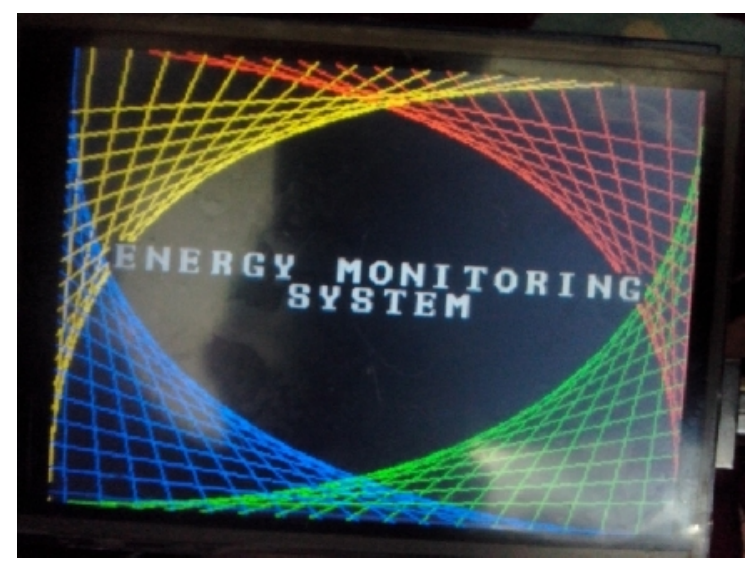

Figure.5 Welcome screen

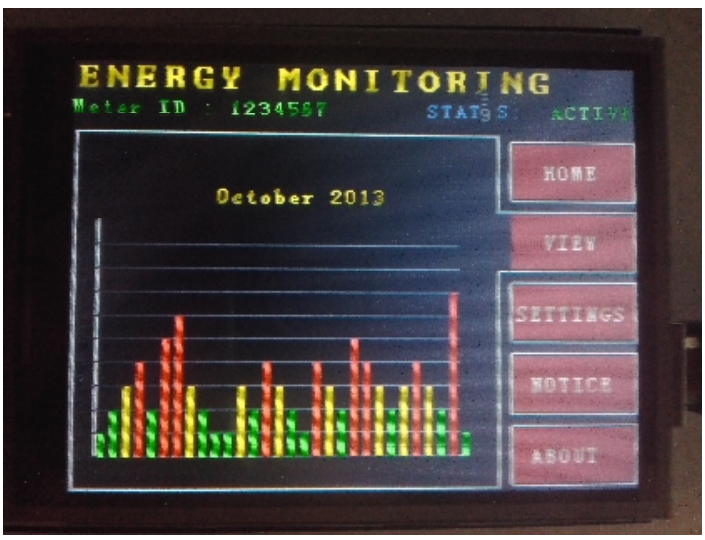

Figure.7. View screen

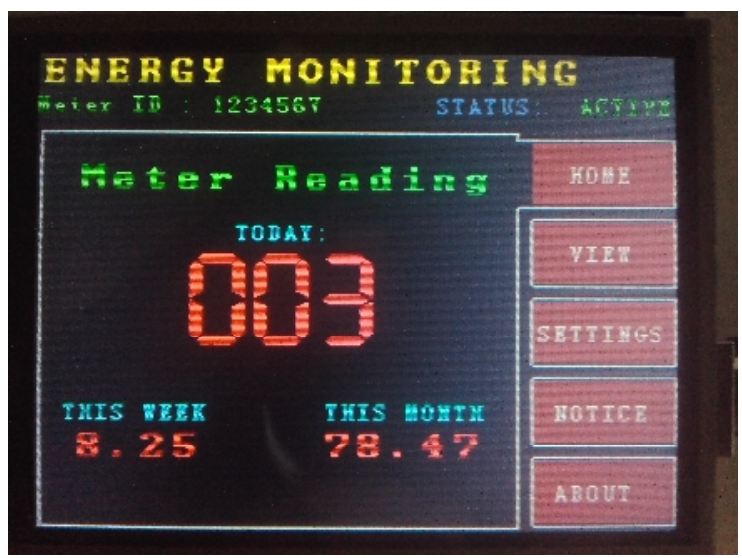

Figure.6. Home Screen

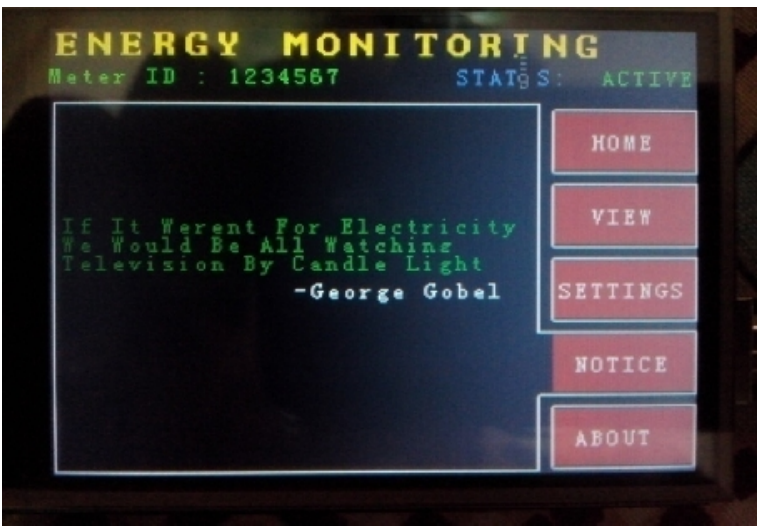

Figure.8 Notice screen

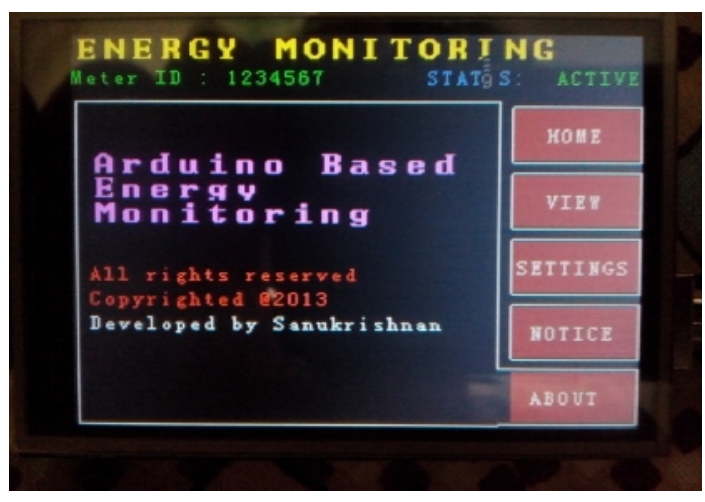

Figure.9About screen

View screen includes the statistics of the entire month. It shows the day by day statistics of the energy consumption. According to the amount consumed, the bar graph will obtain corresponding colours. This makes the analysis so easy. Green indicates low, yellow indicates medium and red 
indicates high power consumption. Figure.7 shows the view screen. Any messages from the authority will be displayed in the notice screen as in Figure.8. This can be used as a reminder for billing, information about the power cuts, etc. About screen showed in Figure. 9 includes the product details.

\subsection{Design of Coordinator}

Coordinator is the central part of the system. It reads the meters regularly and updates the data in to internet. This includes a microcontroller, Real time clock, FSK Modulator and demodulator, MUX/DEMUX circuit, Amplifier, Isolator circuit, LCD and GSM/GPRS module. Figure.5 shows the complete schematic.

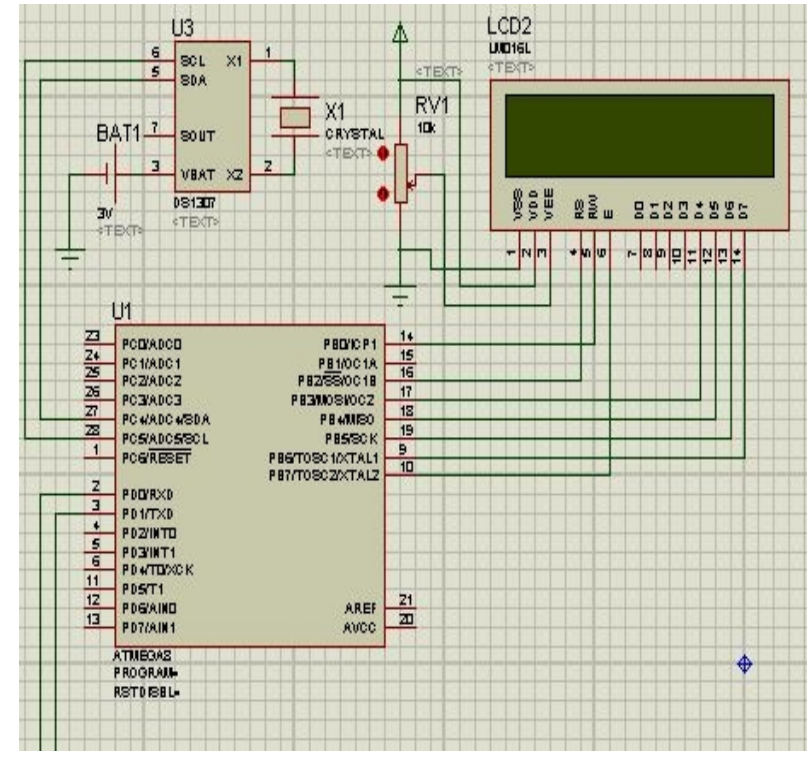

Figure. 5 schematic of main section

Atmega 8 is used as the microcontroller, which is High-performance, Low-power 8-bit Microcontroller with Advanced RISC Architecture. An RTC is interfaced with Atmega 8 by I2C protocol. RTC counts seconds, minutes, hours, date of the month, month, day of the week, and year with leap-year compensation valid up to 2100.The RTC selected here is DS1307 .It is low cost, easy to solder, and can run for years on a very small coin cell (3V CMOS battery) which runs continuously even in power failure.

The UART data can't be connected to the AC lines directly for power line communication. It should be modulated, amplified and isolated. The Tx pin of the microcontroller is directly connected to the modulator input. CD4046 is the IC used. It has 2 phase discriminators and one VCO. Figure.6 and Figure.7 shows FSK modulator and demodulator. 
International Journal of Peer to Peer Networks (IJP2P) Vol.5, No.2, May 2014

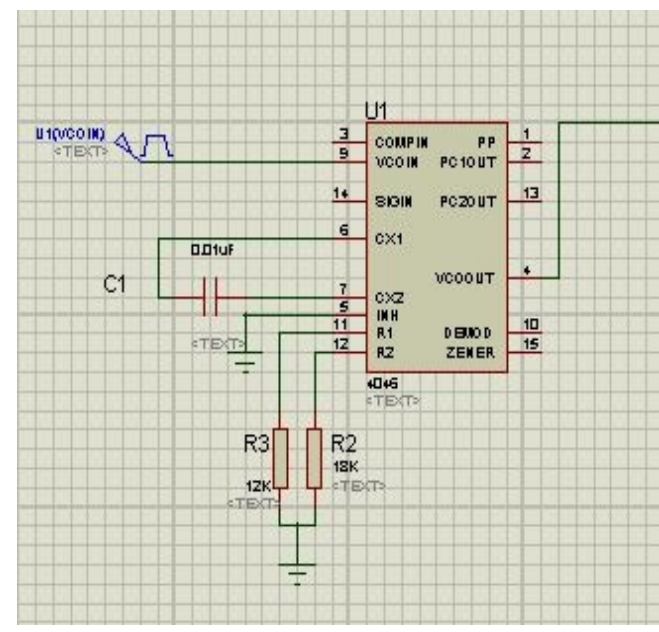

Figure.6 FSK Modulator

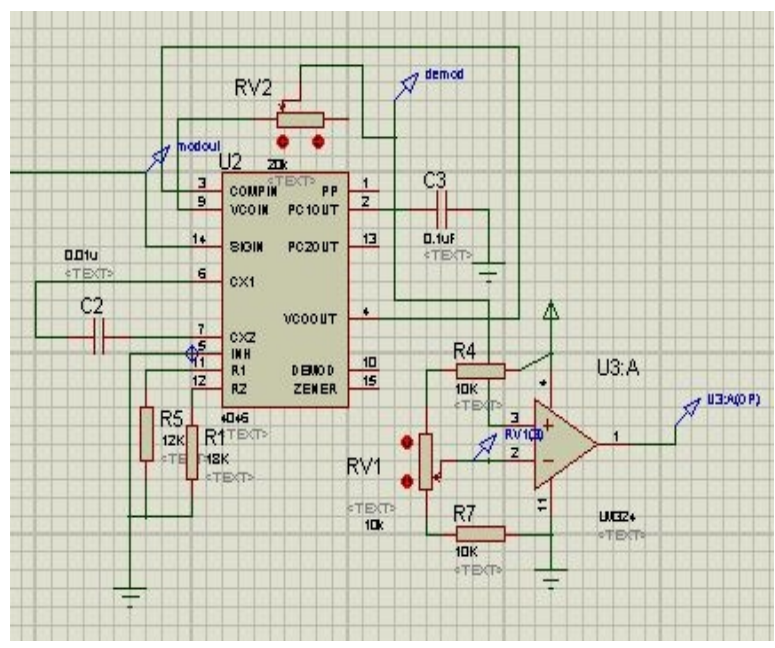

Figure.7 FSK Demodulator

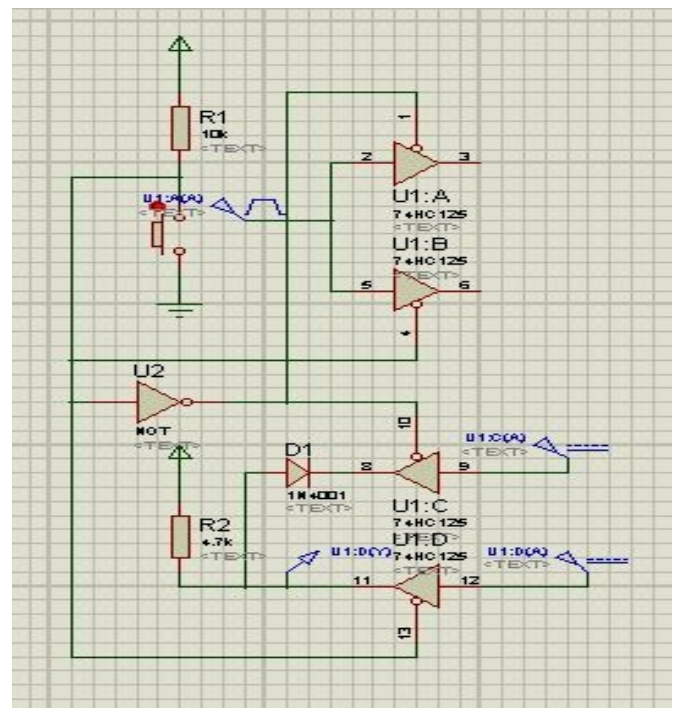

Figure.8 MUX/ DEMUX circuit

Atmega8 is having only one UART, but we have to communicate to the power line as well as the GPRS module. This can be achieved by multiplexing. Use of a buffer $74 \mathrm{HC} 125$ allows this. The control/ enable signal control the direction and via of flow of signal. Figure.8 shows a simple implementation of mux/demux using buffer. U1A and U1B act as the demux and U1c and U1D as the mux. Switch will generate the control signal for the buffers. MUXed output will be available at the node $\mathrm{U} 1 \mathrm{D}(\mathrm{Y})$. 


\section{PlC Algorithm And Protocol}

Certain set of conditions and rules should be obeyed for establishing a reliable power line communication and an efficient monitoring system. Figure.9 shows the Power Line Communication Protocol used.

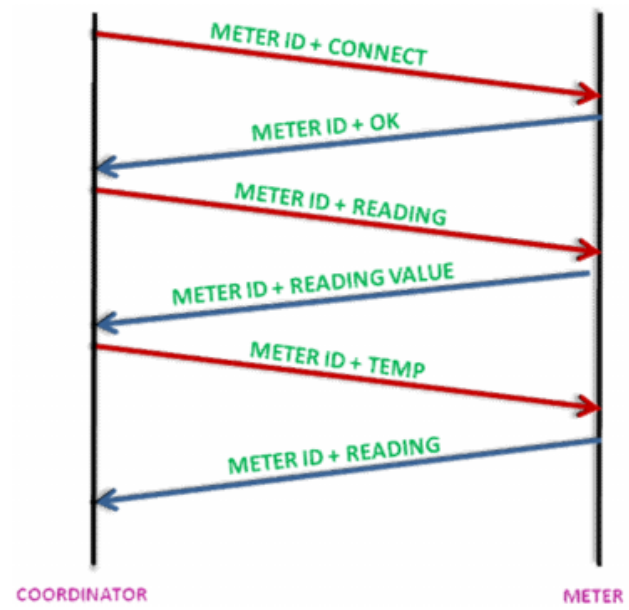

Figure.9 Power Line Communication Protocol

1. [MeterID]+CONNECT : Informs the meter with id "MeterID" that the coordinator is trying to get

2. [MeterID]+OK $\quad$ : Conformation signal from the meter that it is ready for a conversation.

If the coordinator didn't get this conformation even after some duration it will resent the first message and hear for the conformation. If it fail even at its maximum retry limit it will report that the corresponding meter is out of order.

3. [MeterID]+READING : Request to get the reading.

4. [MeterID]+VALUE : Here the "value" will be the corresponding meter reading.

5. [MeterID]+TEMP : Request to resent the reading.

Meter will sent the reading again (the reading stored in buffer while sending the previous message).if meter readings didn't match last 3 steps will be repeated up to a certain value. If it fails all the time, coordinator will inform us that the corresponding meter is malfunctioning. This entire algorithm implemented to establish the protocol described in Figure.9. In addition to that, the Display is getting updated always. Note that this includes the algorithm only for the communication side.Figure. 10 and Figure. 11 shows the algorithm used in meter and coordinator. 
International Journal of Peer to Peer Networks (IJP2P) Vol.5, No.2, May 2014

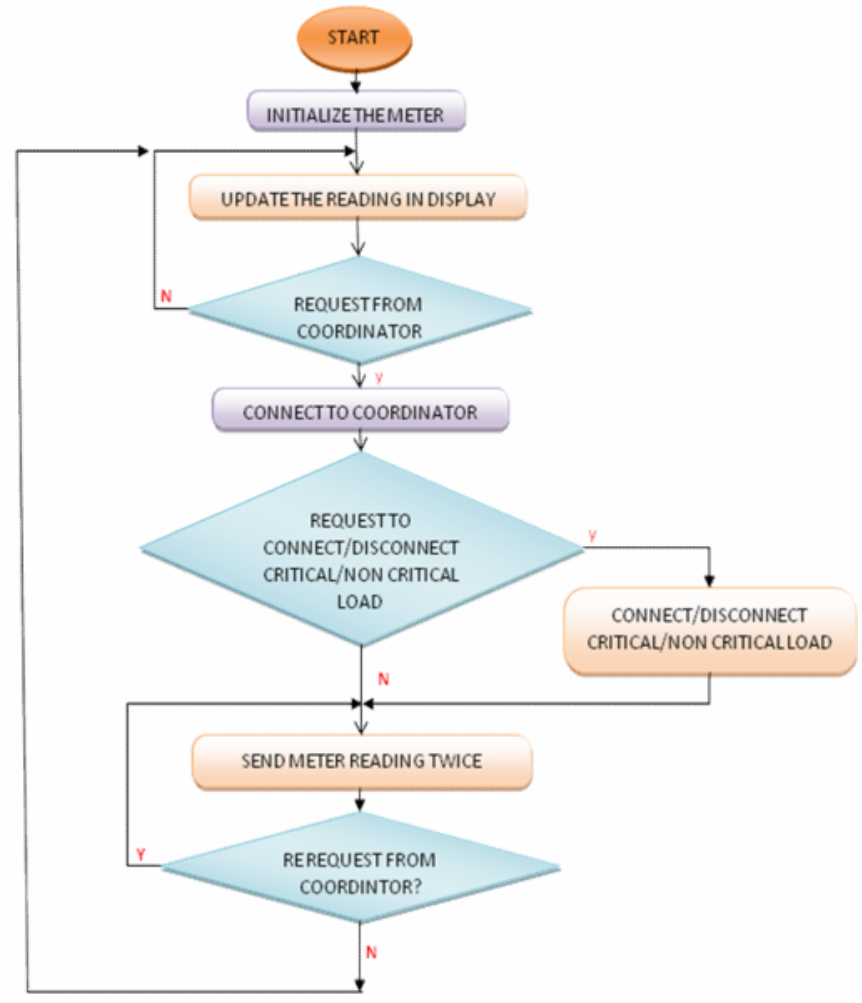

Figure.10 Algorithm for Meter 


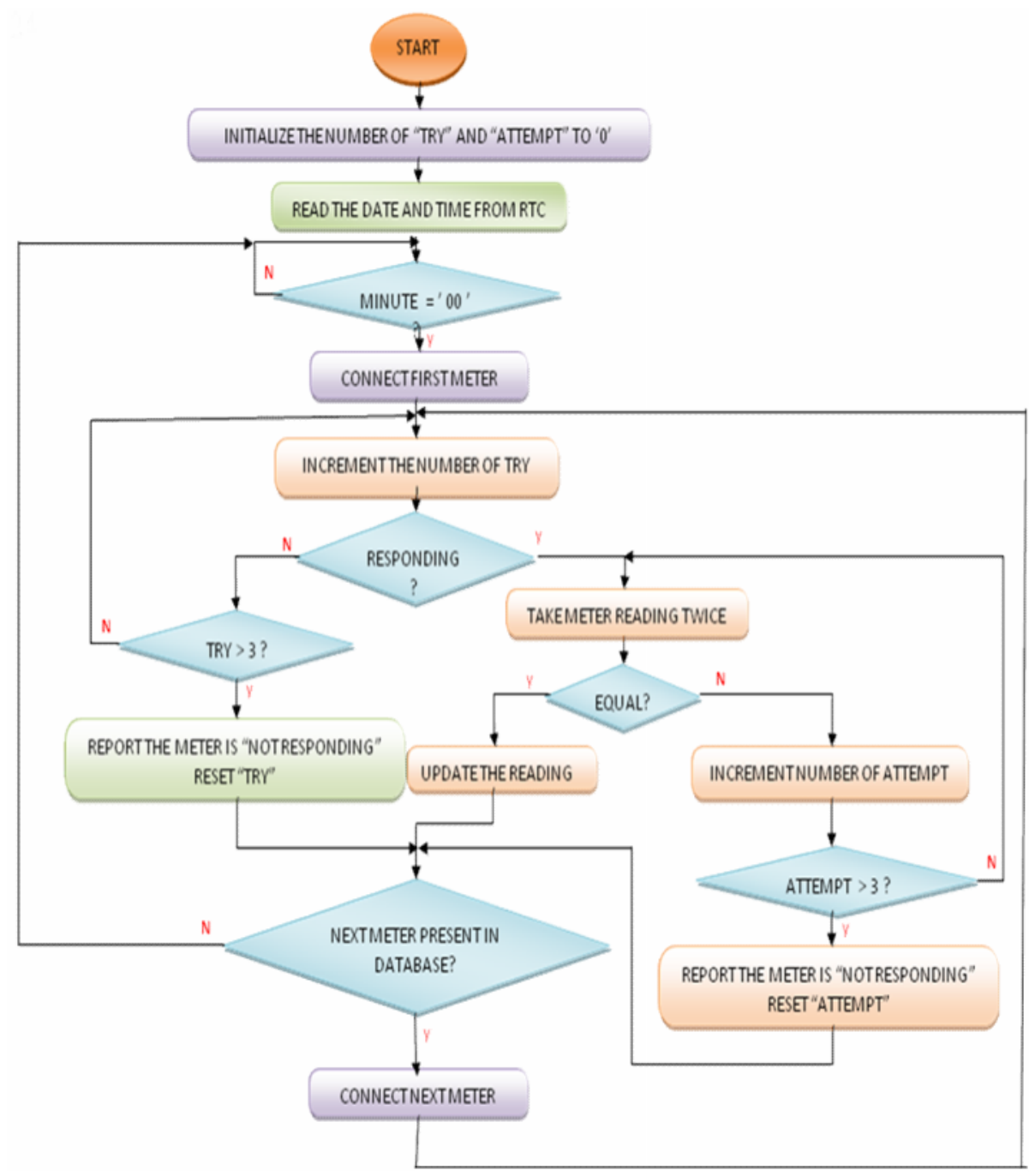

Figure.11 Algorithm for Coordinator

Meter readings will be displayed continuously on the touch screen as in the figureure 6 . At the same time it responds to the coordinator. It will check for connect/disconnect request from the coordinator and take necessary actions. If no such requests are pending it check for meter reading request. Meter reading is sent twice as the response to [METER ID]+READING and [METER ID]+ TEMP. This will repeat forever.

Algorithm of coordinator is little complex here, because it is the master and it should start all the communications. 'Try' and 'attempt' are the integers used to represent the number of tries it take to get connected to the meter and number of times it waits for a correct reading. When these values exceed some threshold value, the coordinator will report this to the controlling station. Otherwise it can simply connect and read the accurate reading from the meter. 


\section{Results}

All the part of communication algorithm is successfully verified by the simulation. Error conditions are intentionally made in the coding to check the complete functionality. Also Arduino board is successfully interfaced with the TFT touch shield. Proper data are displayed and touch is captured successfully.

Figure. 5 to figure. 9 shows the outputs obtained from the arduino touch screen shield. Simulated result of the protocol is shown in the following figurers. The LCD is located at the coordinator and the microcontroller and loads are present at the meter side.

i) Disconnecting all loads

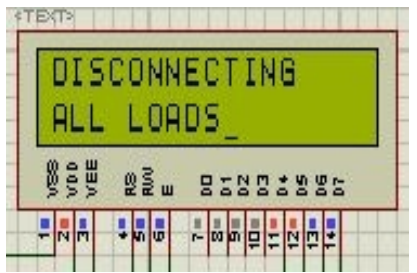

ii) Connecting critical loads
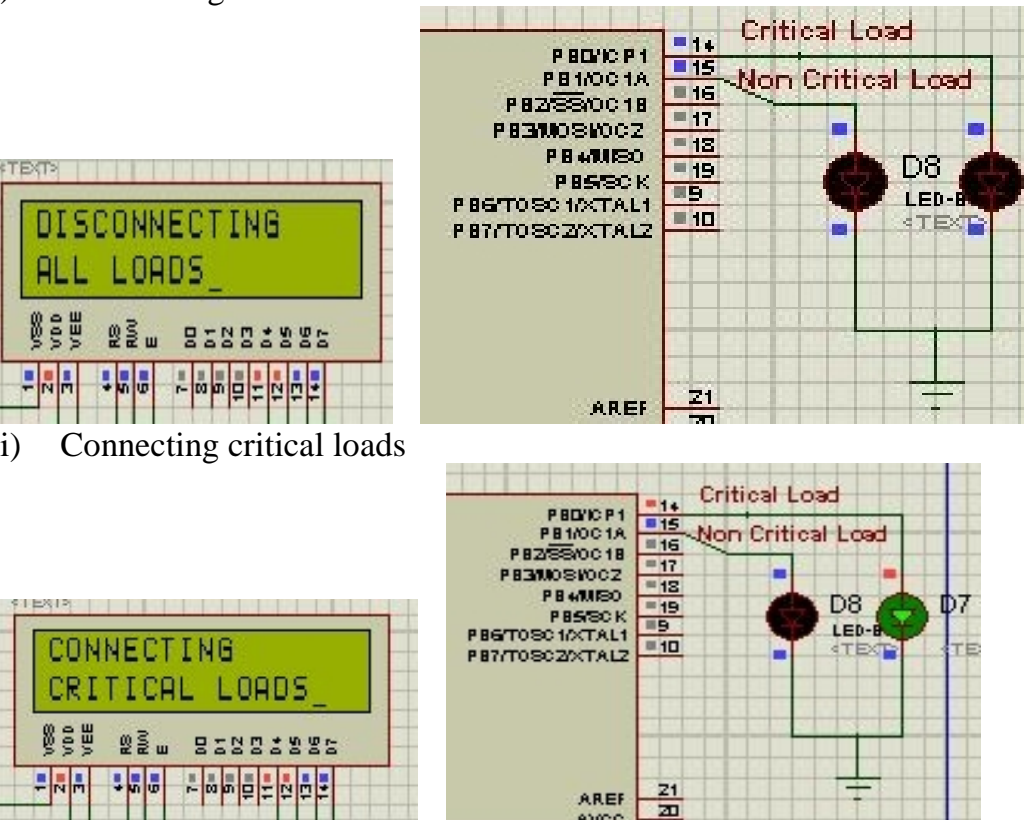

iii) Connecting all loads
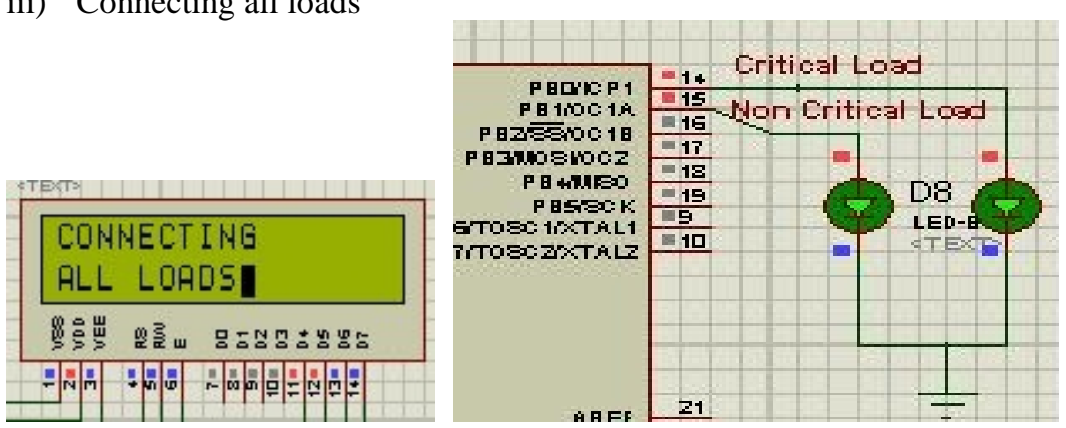

iv) Connecting to meter100 
International Journal of Peer to Peer Networks (IJP2P) Vol.5, No.2, May 2014

v) Taking reading from meter100
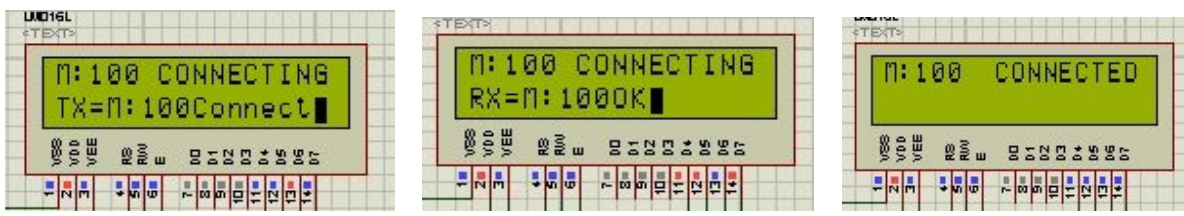

vi) Verifying reading
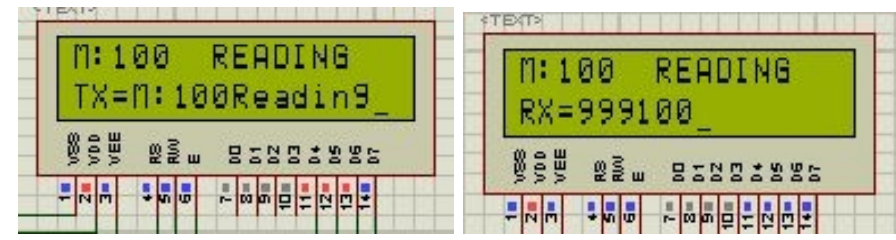

vii) When readings match
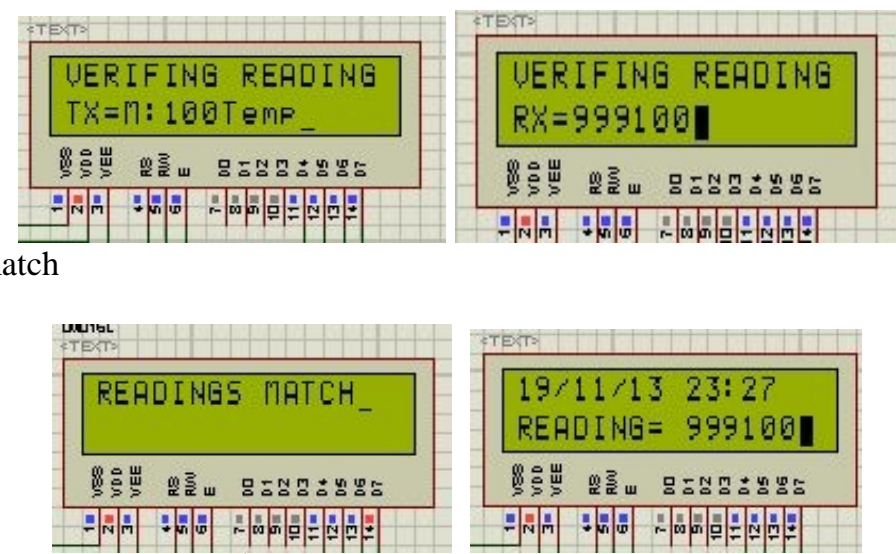

viii) When readings mismatch and $3^{\text {rd }}$ try fails

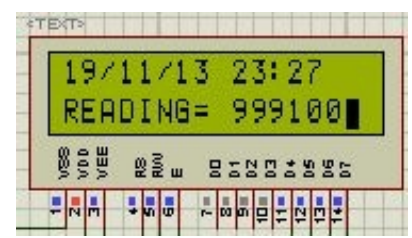

ix) When meter doesn't respond and 3rd attempt fails
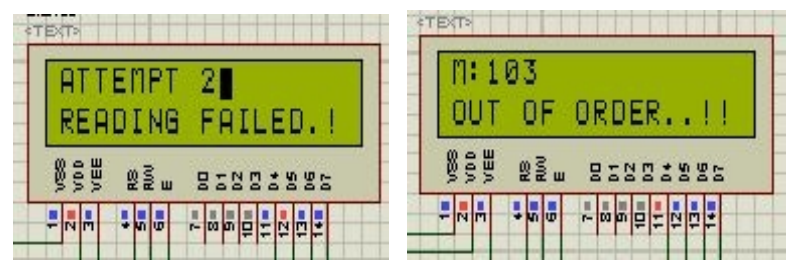

\section{Conclusions}

Arduino uno has sufficient processing speed for manipulating displaying data. It plotted even bar graph without significant delay. Code size can also be accommodated by $32 \mathrm{~kb}$ flash of Arduino Uno. But all the pins are used by the touch screen shield, which disable further improvements. 
Arduino Mega will be the perfect choice.

Power line communication protocols works perfectly under simulation. It is capable for the reactions towards the network. Since FSK is used, the data transfer rate is limited to a rate of 9600 bps.

\section{FUTURE WORKS}

This same system can be extended for the purpose of water supply monitoring and gas monitoring. Without any significant changes in the hardware, this can be achieved. Software that can run in a personal computer can increase the efficiency of the system.

\section{ACKNOWLEDGMENT}

I would like to thank the Department of Electronics and Communication Engineering, HIT, Coimbatore for providing laboratory facilities and opportunity for experimental setup.

\section{REFERENCES}

[1] Ashna.k \& Sudhish N George "GSM BasedAutomatic Energy Meter Reading System with Instant Billing"- IEEE 2013

[2] Abul B a s h a r, M a r u f Ahmad, Sobuj Kumar Ray, \& Asif Ahmed "Economical Way of GPRS Based Fully Automated Energy Metering System"-Global Journal of Computer Science and Technology 2013

[3 ]Nabil Mohammad, Anomadarshi Barua and Muhammad Abdullah Arafat "A Smart Prepaid Energy Metering System to Control Electricity Theft"-2013 International Conference on Power, Energy and Control (ICPEC)

[4] Md. Shams Arman Rupok, Maruf Ahmed, Mr. A.R.N.M Reaz Ul Haque "Design and Implementation of A Novel Remote Metering system using USB GPRS/EDGE Modem” 2011 IEEE

[5] Md. Manirul Islam, Mohiuddin Ahmad, Md. Ajijul Islam, Abu Farzan Mitul, M. F. Malek2, and M. A.Rashid “ Electronic Energy Meter with Remote Monitoring and Billing System" 2012 7th International Conference on Electrical and Computer Engineering

[6] M. Popa "Gateway Design and Implementation in an Automatic Meter Reading System Based on Power Line Communications"

[7] A. Ali , N.A. Razali "Implementation of Automatic Meter Reading (AMR) Using Radio Frequency (RF) Module" 2012 IEEE

[8] Adnan Rashdi, Rafia Malik, Sanam Rashid, Anam Ajmal, Sulaiman Sadiq "Remote Energy Monitoring, Profiling and Control Through GSM Network" 2012 International Conference on Innovations in Information Technology (IIT)

[9] K. S. K. Weranga, D. P. Chandima "Smart Metering for Next Generation Energy Efficiency \& Conservation" IEEE PES ISGT ASIA 20121569564125

[10] A.Geetha, Dr. K. Jamuna "Smart Metering System"

[11] Yujun Bao and Xiaoyan Jiang, "Design of electric Energy Meter for long-distance data information transfers which based upon GPRS", ISA 2009.

[12] H.G.Rodney Tan,C.H, Lee,V.H.Mok, "Automatic power meter reading" IPEC 2007. Vivek Kumar Sehgal,Nitesh Panda, Nipun Rai Handa, "Electronic Energy Meter with instant billing",UKSim Fourth European Modelling Symposium on Computer Modelling and Simulation.

[13] Bharath P, Ananth N, Vijetha S, Jyothi Prakash K. V. ,"Wireless automated digital Energy Meter", ICSET 2008 
International Journal of Peer to Peer Networks (IJP2P) Vol.5, No.2, May 2014

[14] P.K. Lee and L.L. Lai, Fieee, "A practical approach to wireless GPRS on-line power quality monitoring system", Power Engineering Society General Meeting, 2007.

[15] Subhashis Maitra, "Embedded Energy Meter- A new concept to measure the energy consumed by a consumer and to pay the bill", Power System Technology and IEEE.

[16] T El-Djazairy, B J Beggs and I F Stewart, "Investigation of the use of the Global System for Mobile Communications (GSM) network formetering and load management telemetry", Electricity Distribution. Part1: Contributions. CIRED. 14th International Conference and Exhibitionon (IEE Conf. Publ. No. 438).

[17] Li Kaicheng, Liu Jianfeng, Yue Congyuan, Zhang Ming. "Remote power management and meter-reading system based on ARM microprocessor", Precision Electromagnetic Measurements Digest, 2008. CPEM 2008. Conference on Digital Object Identifier.

[18] "An analysis of power tariffs across India" by PHD Chamber Of Commerce And Industry, February 2013

[19] Mahmood, M. Aamir, M. I. Anis, "Design and Implementation of AMR Smart Grid Sytem," Electric Power Conference, IEEE EPEC 2008, pp. 1-6, 2008.

[20] V.C. Gungor, G.P. Hancke, "Industrial Wireless Sensor Networks: Challenges, Design Principles, and Technical Approaches," IEEE Trans. On Industrial Electronics, vol. 56, no. 10, pp.4258-4265, 2009.proc.of IEEE International Conference on IndustrialElectronics, Control, and Instrumentation, vol. 1.

[21] L. Hong and L. Ning. "Design and Implementation of Remote Intelligent Management System for City Energy Resources based on Wireless Network", Study of Computer Application, no.12, pp. 237-239, 2004. pp. 631-636, 1996.

[22] C. Yin-kang, L. Xiang-yang and X. Jing. "The Hardware Design of Concentrator for Wireless Intelligent Meter Reading System”, Element and IC,no. 1, pp. 37-39, 2005.

[23] P.K. Lee, L. L. Lai, "A Practical Approach to Wireless GPRS On-Line Power Quality Monitoring System," Proc. of the IEEE PES General Meeting, June 2007.

[24] Haque, Md. Mejbaul, et al., "Microcontroller Based Single Phase Digital Prepaid Energy Meter for Improved Metering and Billing System", International Journal of Power Electronics and Drive System (IJPEDS), Vol.1, No.2, December 2011, pp.139-147.

[25] Quazi, Irfan, et al., "Pre-paid Energy Meter based on AVR Microcontroller", International Journal of Engineering Research and Applications (IJERA),Vol. 1, Issue 4, pp. 1879-1884.

[26] S.W. Lee, C.S. Wu, W. M.S. Chiou and K.T. Wu."Design of an Automatic Meter Reading System",

[27] P.M. Kanabar, M.G. Kanabar, W. El-Khattam, T.S. Sidhu, and A. Shami, "Evaluation of Communication Technologies for IEC 61850 Based Distribution Automation System with Distributed Energy Resources", Proc. of the IEEE PES General Meeting, Calgary, July 26-30, 2009

\section{Authors}

Mr. Sanukrishnan S.B. Pursuing M.E. in VLSI Design and Embedded Systems, from Hindusthan Institute of Technology, Coimbatore under Anna University, Chennai. He Received B.Tech degree from Kannur university in Electronics and Communicatioin Engineering in 2012 with 'Honours' certificate. He is currently an intern in Ulive Embedded solutions, Coimbatore. He is selected as the 'Best Engineer' by the technical competition conducted by CITV Vadakara, and got many prizes for the event line follower. His interests include automation, energy consumption and robotics.

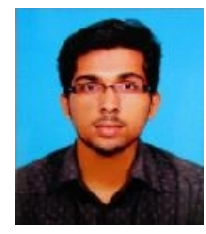

